\title{
Experience with Vildagliptin in Patients $\geq 75$ Years with Type 2 Diabetes and Moderate or Severe Renal Impairment
}

\author{
Anja Schweizer $\cdot$ Sylvie Dejager
}

To view enhanced content go to www.diabetestherapy-open.com

Received: May 6, 2013 / Published online: July 3, 2013

(c) The Author(s) 2013. This article is published with open access at Springerlink.com

\section{ABSTRACT}

Introduction: Patients with type 2 diabetes (T2DM) are at increased risk for renal impairment (RI) and, in addition, there is an age-related decline in renal function. At the same time, T2DM treatment is more complex and treatment options are more limited in elderly patients as well as patients with RI, with the patient population $\geq 75$ years with moderate or severe RI posing unique challenges, in particular, the high risk and more severe consequences of hypoglycemia. It was, therefore, of interest to assess the efficacy and tolerability of the dipeptidyl peptidase- 4

\section{A. Schweizer $(\square)$}

Novartis Pharma AG, Postfach, 4002 Basel,

Switzerland

e-mail: anja.schweizer@novartis.com

\section{S. Dejager}

Novartis Pharma S.A.S, Rueil-Malmaison, France

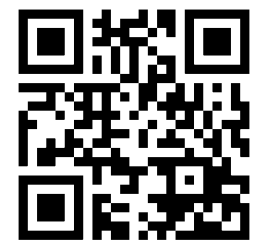

Enhanced content for this article is available on the journal web site: www.diabetestherapy-open.com inhibitor vildagliptin in patients with T2DM $\geq 75$ years who also have moderate or severe RI. Methods: In this sub-analysis of data derived from a previously described randomized, doubleblind, parallel-group, 24-week study, 105 patients (50 randomized to vildagliptin $50 \mathrm{mg}$ qd and 55 to placebo) $\geq 75$ years (mean age $\sim 78$ years) with T2DM and moderate or severe RI (mean baseline estimated glomerular filtration rate $\sim 35 \mathrm{ml} / \mathrm{min} /$ $1.73 \mathrm{~m}^{2}$ ) were included.

Results: The adjusted mean change in glycated hemoglobin $\left(\mathrm{HbA}_{1 \mathrm{c}}\right)$ with vildagliptin was $-1.0 \%$ from a baseline of $7.8 \%$ (between-group difference $-0.8 \% ; p<0.001)$. This improvement in glycemic control was not associated with an increased risk of hypoglycemia; the rate of confirmed hypoglycemia was 0.49 events per patient-year with vildagliptin and 0.96 events per patient-year with placebo (not significant). Weight remained stable with vildagliptin treatment. Adverse events (AEs) (58.0\% vs. $72.7 \%)$, serious AEs $(14.0 \%$ vs. $16.4 \%)$, discontinuations due to AEs (4.0\% vs. 9.1\%) and deaths ( $0 \%$ vs. $5.5 \%$ ) were reported at a comparable or lower frequency in patients receiving vildagliptin versus patients receiving placebo. 
Conclusion: In this uniquely fragile elderly population $\geq 75$ years with T2DM and moderate or severe RI, vildagliptin was well tolerated and efficacious, with no increase in the rate of hypoglycemia compared to placebo despite the marked improvement in glycemic control.

Keywords: Dipeptidyl peptidase-4; Elderly; Renal impairment; Type 2 diabetes; Vildagliptin

\section{INTRODUCTION}

The number of elderly individuals suffering from type 2 diabetes (T2DM) is continuously growing worldwide. This is related to the overall aging of the population as well as to a continuous increase in the prevalence of T2DM with age, reaching about $20 \%$ in adults aged 75 years or older [1]. These elderly patients have an increased prevalence of T2DM-related morbidity and mortality, physical disability and frailty, cognitive disorders and, in particular, micro- and macrovascular co-morbidities, such as congestive heart failure and renal impairment (RI) [2].

Diabetes is the leading causes of chronic kidney disease [3], with T2DM patients accounting for about $1 / 3$ of all cases of end stage renal disease (ESRD) requiring dialysis [4]. In addition, there is also an age-related decline in kidney function [5]. Ultimately, between $25 \%$ and $40 \%$ of patients with T2DM will develop RI [6]. In a large-scale French survey, for example, $28 \%$ of the population of patients with $\mathrm{T} 2 \mathrm{DM} \geq 65$ years had moderate RI and this increased to $37 \%$ for patients aged $75-79$ years [7].

The elderly population with T2DM and moderate or severe RI is a uniquely fragile population and effective treatment in this vulnerable population poses special challenges. These include a high prevalence of polypharmacy, which increases the risk of drug-drug interactions, presence of multiple co-morbidities, and the paucity of clinical data in this population. Importantly, treatment options are more limited and/or complex in this population due to contraindications, differential clearance and/or metabolism of anti-hyperglycemic agents, need for dose adjustment and/or regular monitoring. In addition, there is a higher risk for side effects, in particular, a high susceptibility and dangerousness of hypoglycemia. The risk of hypoglycemia associated with drug treatment (insulin secretagogues and insulin) increases markedly with age $[2,8]$ and hypoglycemia in the elderly is associated with more severe consequences and complications [2]. The risk of adverse effects is further increased by a marked unawareness of hypoglycemia in the elderly population, leading to more frequent and severe events $[9,10]$. Furthermore, RI is also associated with an increased incidence of hypoglycemia due to decreased renal neoglycogenesis [11]. For example, in a retrospective cohort analysis, the incidence of hypoglycemia (glucose $<70 \mathrm{mg} / \mathrm{dL}$ ) was 10.72 events per 100 patient-months in diabetic patients with chronic kidney disease versus 5.33 in those without chronic kidney disease [12]. Additionally, RI is associated with differential clearance and/or metabolism of several anti-hyperglycemic agents; in particular, consequent overexposure to insulin secretagogues is often linked to an increased risk of hypoglycemia [13]. Similarly, the difficulty with insulin dose selection due to impaired catabolism and clearance of exogenous insulin in patients with RI further increases the risk of hypoglycemia [13]. 
Vildagliptin is an inhibitor of dipeptidyl peptidase 4 (DPP-4) that extends the mealinduced increases in the levels of the incretin hormones, glucagon-like peptide 1 (GLP-1) and glucose-dependent insulinotropic polypeptide (GIP), thereby improving the sensitivity and responsiveness of pancreatic $\alpha$-cells and $\beta$-cells to glucose [14]. This results in glucose-sensitive modulation of insulin and glucagon secretion, improving both fasting and postprandial glycemic control, with a low risk of hypoglycemia [14]. A hypoglycemia risk similar to placebo has consistently been seen with vildagliptin across a wide spectrum of patients/disease [15], including elderly patients $[2,16]$, patients with RI [17-19] and/or patients treated with insulin [20]. This included data from a dedicated 24-week study of vildagliptin $50 \mathrm{mg}$ qd in patients with moderate or severe RI [17]. In this large study $\sim 20 \%$ of patients were 75 years or older, which provided an opportunity to assess the efficacy and tolerability of vildagliptin in this particularly vulnerable and difficult-to-treat elderly T2DM patient population with RI. Accordingly, the authors report here the experience with vildagliptin in patients $\geq 75$ years with T2DM and moderate/severe RI based on a subanalysis of the afore-mentioned study [17].

\section{MATERIALS AND METHODS}

\section{Patients and Study Design}

This was a post hoc sub-analysis of data from a previously described [17] multi-center, randomized, double-blind, parallel-group, 24-week study that assessed safety and efficacy of vildagliptin (50 mg qd) versus placebo in 515 patients with T2DM and moderate $(n=294)$ or severe $(n=221)$ RI. The key entry criteria for this trial included age of $18-85$ years, body mass index (BMI) of $18-42 \mathrm{~kg} / \mathrm{m}^{2}$, glycated hemoglobin $\left(\mathrm{HbA}_{1 \mathrm{c}}\right)$ of $6.5-10 \%$ and $\mathrm{T} 2 \mathrm{DM}$ either untreated or treated with a sulfonylurea (SU), alpha-glucosidase inhibitor (AGI), thiazolidinedione (TZD), insulin, meglitinide or a combination of agents provided that doses were stable for at least 4 weeks before the first study visit. Patients also had to continue their current diet/exercise regimen and background therapy unchanged throughout the duration of the study. The diet or caloric intake was not specifically monitored during the study. Addition or intensification of insulin therapy was defined as initiating rescue medication. After a 2-week single-blind, placebo run-in period, eligible patients were randomized (baseline, BL) to vildagliptin (50 mg qd, $n=289)$ or placebo $(n=226)$. The detailed design of this study was described previously [17].

The data analysis presented here includes only patients with age $\geq 75$ years, resulting in 105 patients with moderate or severe RI [estimated glomerular filtration rate (eGFR) $\geq 30$ to $<50 \mathrm{ml} / \mathrm{min} / 1.73 \mathrm{~m}^{2}$ and $<30 \mathrm{ml} / \mathrm{min} /$ $1.73 \mathrm{~m}^{2}$, respectively] contributing to the subanalysis.

\section{Study Assessments}

$\mathrm{HbA}_{1 \mathrm{c}}$, fasting plasma glucose (FPG), and weight were regularly assessed at 4 -week intervals. The laboratory assessments were performed by a central laboratory [Covance (Geneva, Switzerland, Singapore, or Indianapolis, IN, USA)]. Responder analysis was also performed as described below.

Hypoglycemia was defined as symptoms suggestive of low blood glucose confirmed by self-monitored blood glucose (SMBG) 
measurement $<3.1 \mathrm{mmol} / \mathrm{l}$ plasma glucose equivalent. Severe hypoglycemia was defined as any episode requiring assistance of another party (whether or not a confirmatory SMBG measurement was available).

All adverse events (AEs) were recorded and assessed by the investigator for severity and possible relationship to study medication. GFR was estimated by the Modification of Diet in Renal Disease study method (MDRD).

\section{Statistical Analysis}

The total number of patients and demographic and clinical characteristics are presented.

The adjusted mean changes $(\mathrm{AM} \Delta)$ in $\mathrm{HbA}_{1 \mathrm{c}}$, FPG and weight from BL to endpoint [with final observation carried forward (LOCF)] were compared between treatments using an analysis of covariance (ANCOVA) model with baseline value, background therapy, pooled center, and treatment as covariates. Data were censored at initiation of rescue medication. Responder rates (percentage of patients with baseline $\mathrm{HbA}_{1 \mathrm{c}} \geq 7.5 \%$ achieving endpoint $\mathrm{HbA}_{1 \mathrm{c}}<7.5 \%$ ) were assessed by treatment and compared by Fisher's exact test. For hypoglycemia, event rates per patient-year (defined as number of events/total subject year exposure) were compared between treatments with inference based on a normal approximation of the Poisson distribution. In addition, the number of patients experiencing events and the number of events were summarized descriptively. Safety data were summarized descriptively by treatment.

\section{Ethics and Good Clinical Practice}

The study underlying this sub-analysis was conducted in accordance with the Helsinki Declaration of 1975, as revised in 2000 and 2008 and International Conference on Harmonization/ Good Clinical Practice guidelines. The study protocol was approved by an independent ethics committee/institutional review board (IRB) at each site and all patients provided written informed consent.

\section{RESULTS}

\section{Demography}

One hundred and five patients [50 in the vildagliptin (50 $\mathrm{mg} \mathrm{qd}$ ) group and 55 in the placebo group] with moderate or severe RI and aged 75 years or older at study entry were included in this analysis. Table 1 summarizes the demographic and clinical characteristics in the randomized population. These elderly patients with moderate or severe RI had a mean age of 78.1 years and a mean eGFR of $35.3 \mathrm{ml} / \mathrm{min} / 1.73 \mathrm{~m}^{2}$. Nearly $1 / 3$ of patients $\geq 75$ years had severe RI and the remaining about $2 / 3$ of patients had moderate RI. The randomized patients had a mean $\mathrm{HbA}_{1 \mathrm{c}}$ of $7.8 \%$, mean FPG of $8.5 \mathrm{mmol} / \mathrm{L}$ and mean BMI of $30.5 \mathrm{~kg} / \mathrm{m}^{2}$, and were treated mainly with either insulin ( $\sim 55 \%)$ or oral anti-diabetic drug (OAD) monotherapy $(\sim 25 \%)$, or a combination of insulin and OAD $(\sim 13 \%)$. As expected, patients had long-standing T2DM (mean duration of 16.2 years, with $2 / 3$ of patients being diagnosed with $\mathrm{T} 2 \mathrm{DM}$ for $\geq 10$ years), nearly all patients $(96.2 \%)$ had hypertension and $>2 / 3$ of patients (68.6\%) had dyslipidemia. Furthermore, in line with their advanced age and T2DM, more than half of the patients (53.3\%) had a high cardiovascular (CV) risk status, defined as previous history of $\mathrm{CV}$ and cerebrovascular (CCV) events in the Standard MedDRA Queries (SMQs) of 'ischemic heart disease, cardiac failure, ischemic cerebrovascular conditions and/or embolic/ 
Table 1 Patient demographic and clinical characteristics (randomized population)

\begin{tabular}{|c|c|c|}
\hline Mean \pm s.d. or $n(\%)$ & $\begin{array}{l}\text { Vildagliptin } \\
50 \mathrm{mg} \text { qd }\end{array}$ & Placebo \\
\hline$n$ & 50 & 55 \\
\hline Mean age (years) & $78.0 \pm 2.5$ & $78.3 \pm 2.7$ \\
\hline \multicolumn{3}{|l|}{ Sex } \\
\hline Male & $26(52.0)$ & $30(54.5)$ \\
\hline Female & $24(48.0)$ & $25(45.5)$ \\
\hline \multicolumn{3}{|l|}{ Race } \\
\hline White & $44(88.0)$ & $43(78.2)$ \\
\hline Asian & $3(6.0)$ & $5(9.1)$ \\
\hline Hispanic/latino & $3(6.0)$ & $6(10.9)$ \\
\hline All other & $0(0.0)$ & $1(1.8)$ \\
\hline Mean $\mathrm{HbA}_{1 \mathrm{c}}(\%)$ & $7.8 \pm 1.0$ & $7.9 \pm 0.8$ \\
\hline Mean FPG (mmol/L) & $8.8 \pm 3.2$ & $8.2 \pm 3.1$ \\
\hline Mean weight $(\mathrm{kg})$ & $81.2 \pm 13.8$ & $79.9 \pm 13.9$ \\
\hline Mean BMI $\left(\mathrm{kg} / \mathrm{m}^{2}\right)$ & $31.0 \pm 4.5$ & $30.0 \pm 4.4$ \\
\hline $\begin{array}{l}\text { Mean duration of T2DM } \\
\text { (years) }\end{array}$ & $14.0 \pm 9.7$ & $18.1 \pm 10.0$ \\
\hline \multicolumn{3}{|c|}{ Disease duration group (years) } \\
\hline$\geq 5$ & $43(86.0)$ & $47(85.5)$ \\
\hline$\geq 10$ & $29(58.0)$ & $41(74.5)$ \\
\hline $\begin{array}{l}\text { Mean eGFR (MDRD) } \\
\left(\mathrm{ml} / \mathrm{min} / 1.73 \mathrm{~m}^{2}\right)\end{array}$ & $35.5 \pm 9.4$ & $35.1 \pm 9.5$ \\
\hline \multicolumn{3}{|l|}{ eGFR group } \\
\hline Moderate $(\geq 30$ to $<50)$ & $36(72.0)$ & $35(63.6)$ \\
\hline Severe $(<30)$ & $14(28.0)$ & $20(36.4)$ \\
\hline \multicolumn{3}{|c|}{ Previous antidiabetic medication $[n(\%)]$} \\
\hline Drug-naive & $4(8.0)$ & $1(1.8)$ \\
\hline Insulin monotherapy & $26(52.0)$ & $32(58.2)$ \\
\hline Insulin and $\mathrm{OAD}$ & $3(6.0)$ & $11(20.0)$ \\
\hline OAD monotherapy & $17(34.0)$ & $9(16.4)$ \\
\hline $\begin{array}{l}\text { OAD combination } \\
\text { therapy }\end{array}$ & $0(0.0)$ & $2(3.6)$ \\
\hline
\end{tabular}

Table 1 continued

\begin{tabular}{|c|c|c|}
\hline Mean \pm s.d. or $n(\%)$ & $\begin{array}{l}\text { Vildagliptin } \\
50 \mathrm{mg} \text { qd }\end{array}$ & Placebo \\
\hline \multicolumn{3}{|l|}{ CV history } \\
\hline Hypertension & $48(96.0)$ & $53(96.4)$ \\
\hline Dyslipidemia & $36(72.0)$ & $36(65.5)$ \\
\hline High CV risk status ${ }^{a}$ & $26(52.0)$ & $30(54.5)$ \\
\hline \multicolumn{3}{|c|}{$\begin{array}{l}\text { Concomitant medications at } \mathrm{BL} \text { (in addition to any anti- } \\
\text { diabetic medications) }\end{array}$} \\
\hline$\geq 5$ Medications & $42(84.0)$ & $47(85.5)$ \\
\hline $\begin{array}{l}\text { Anti-hypertensive } \\
\text { medications }\end{array}$ & $47(94.0)$ & $53(96.4)$ \\
\hline $\begin{array}{l}\text { Lipid-lowering } \\
\text { medications }\end{array}$ & $34(68.0)$ & $34(61.8)$ \\
\hline
\end{tabular}

$B L$ baseline, $B M I$ body mass index, $C V$ cardiovascular, $F P G$ fasting plasma glucose, GFR glomerular filtration rate, $H b A_{1 c}$ glycated hemoglobin, MDRD modification of diet in renal disease, $O A D$ oral anti-diabetic drug, s.d. standard deviation, $S M Q$ standardized MedDRA query, $S U$ sulfonylurea, $T 2 D M$ type 2 diabetes

${ }^{a}$ High CV risk status includes patients with a previous history of CV and cerebrovascular events in the SMQs of "ischemic heart disease, cardiac failure, ischemic cerebrovascular conditions and/or embolic thrombotic events, arterial”

thrombotic events arterial'. These disease characteristics are also reflected in the number and nature of concomitant medications, with $84.8 \%$ of patients taking $\geq 5$ other medications (in addition to their anti-diabetic treatment), 95.2\% receiving anti-hypertensive medications and $64.8 \%$ being treated with lipid-lowering agents. The demographic and clinical characteristics were overall comparable between the vildagliptin and placebo groups.

\section{EFFICACY}

In the patients $\geq 75$ years with $\mathrm{T} 2 \mathrm{DM}$ and moderate/severe RI receiving vildagliptin 
$50 \mathrm{mg}$ qd added to background therapy, the $\mathrm{AM} \Delta$ in $\mathrm{HbA}_{1 \mathrm{c}}$ from baseline $(7.8 \% \pm 0.2 \%)$ to week 24 endpoint was $-1.0 \% \pm 0.2 \%$, while in the patients receiving placebo added to background therapy the $\mathrm{AM} \Delta$ from baseline $(7.9 \% \pm 0.1 \%)$ to endpoint was $-0.2 \% \pm 0.2 \%$ (Fig. 1a). This resulted in a significant betweengroup difference (vildagliptin-placebo) of $-0.8 \% \pm 0.2 \% \quad(p<0.001)$. The percentage of vildagliptin-treated patients (with baseline $\mathrm{HbA}_{1 \mathrm{c}}>7.5 \%$ achieving endpoint $\mathrm{HbA}_{1 \mathrm{c}}$ $\leq 7.5 \%$, a target consistent with the vulnerable patient population $[3,21,22]$, was nearly twice that reported in the placebo group (51.9\% vs. $26.3 \%)$.

FPG also decreased with vildagliptin. The $\mathrm{AM} \Delta$ in FPG in the vildagliptin group was $-1.1 \pm 0.6 \mathrm{mmol} / \mathrm{L}$ (baseline $8.9 \pm 0.5 \mathrm{mmol} /$ $\mathrm{L})$; however, the between-treatment difference

A
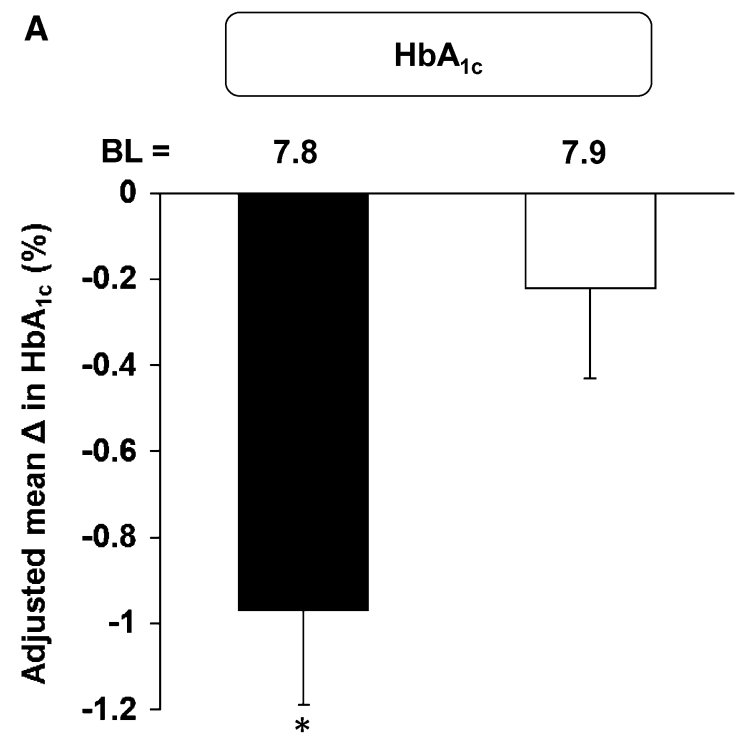

$(-0.9 \pm 0.5 \mathrm{mmol} / \mathrm{L})$ did not achieve statistical significance $(p=0.088)$.

Body weight remained stable in the vildagliptin group; baseline weight averaged $81.1 \pm 2.0 \mathrm{~kg}$ and the $\mathrm{AM} \Delta$ was $0.4 \pm 0.7 \mathrm{~kg}$. In the placebo group, the $\mathrm{AM} \Delta$ was $-1.0 \pm 0.7 \mathrm{~kg}$ from a baseline of $79.8 \pm 1.9 \mathrm{~kg}$ ( $p=0.015 \mathrm{vs}$. vildagliptin).

The markedly lower glucose level achieved with vildagliptin vs. placebo added to background therapy was not associated with an increased risk of hypoglycemia. Figure $1 b$ shows the frequency of confirmed hypoglycemia over 24 weeks of treatment. The rate of hypoglycemia was 0.49 events per patient-year with vildagliptin and 0.96 events per patient-year with placebo (not significant; $p=0.970$ ). Expressed in absolute number of events, in the vildagliptin group 5 patients
B

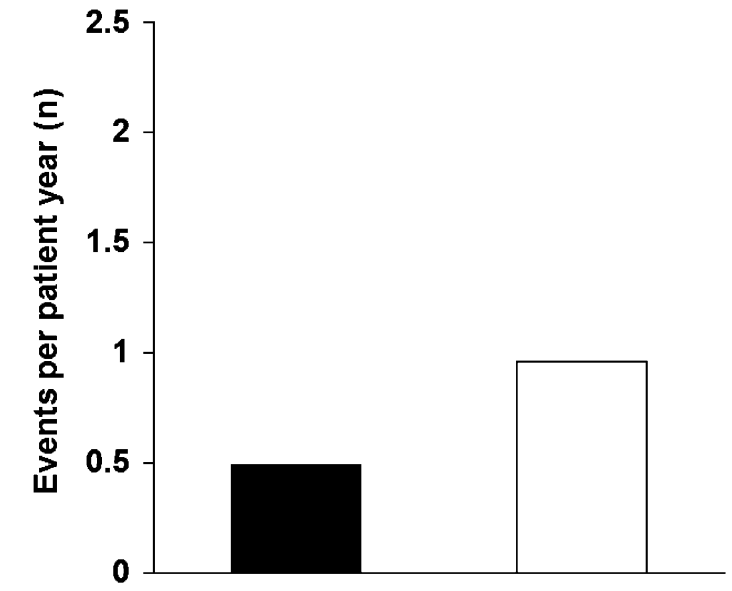

Vildagliptin $50 \mathrm{mg}$ qd $\square$ Placebo

Fig. 1 a Adjusted mean $( \pm S E M)$ change from baseline to week 24 endpoint in $\mathrm{HbA}_{1 \mathrm{c}}$ in patients adding vildagliptin $50 \mathrm{mg}$ qd $(n=49)$ or placebo $(n=55)$ to their ongoing background therapy; $* p<0.001$ (between-group difference). An ANCOVA model with baseline value, background therapy, pooled center and treatment as covariates was used. b Events per patient-year of hypoglycemia during 24-week treatment with vildagliptin $50 \mathrm{mg}$ qd $(n=50)$ or placebo $(n=55)$ added to their ongoing background therapy; $p=0.970$ (between-group difference). $B L$ baseline 
reported a total of 11 events, while in the placebo group 4 patients reported a total of 23 events. Furthermore, severe hypoglycemia (i.e. requiring assistance of another party) was rare in both treatment groups (experienced by 1 patient in the vildagliptin group and 0 patients in the placebo group), and no patients in either treatment group discontinued due to hypoglycemia.

\section{Safety and Tolerability}

The overall AE profile was similar in elderly patients with moderate/severe RI receiving vildagliptin or placebo (Table 2 ).

Adverse events (58.0\% vs. $72.7 \%)$ and discontinuations due to AEs (4.0\% vs. 9.1\%) were reported with a somewhat lower frequency in elderly patients with moderate/severe RI receiving vildagliptin than in patients receiving placebo, and the incidence of serious AEs (SAEs) was similar in the two treatment groups (14.0\% vs. $16.4 \%$ ) (Table 2 ). No patient in the vildagliptin treatment group died, while 3 patients (5.5\%) died in the placebo group (1 myocardial infarction, 1 cardiogenic shock, and 1 upper gastrointestinal hemorrhage) (Table 2).

When system organ classes (SOCs) of interest in this elderly patient population with moderate/severe RI were analyzed (Table 2), lower incidences of AEs were reported with vildagliptin vs. placebo in the SOCs of cardiac disorders (4.0\% vs. $18.2 \%$; the difference not being driven by a particular type of event) and gastrointestinal disorders ( $8.0 \%$ vs. $20.0 \%$; with the largest difference seen for diarrhea). The $\mathrm{AE}$ rates in the SOCs of infections and infestations, musculoskeletal and connective tissue disorders, nervous system disorders and skin and subcutaneous tissue disorders were overall similar between vildagliptin and placebo. As further detailed in Table 2, the most commonly reported specific AEs were edema (12.0\% with vildagliptin vs. $16.4 \%$ with placebo), nasopharyngitis (12.0\% vs. $7.3 \%)$ and dizziness $(4.0 \%$ vs. $14.5 \%)$. Most of the AEs in both treatment groups were mild or moderate, with only $8.0 \%$ of patients in the vildagliptin group and $12.7 \%$ of patients in the placebo group experiencing severe events.

Table 2 Adverse events (safety set)

\begin{tabular}{|c|c|c|}
\hline & $\begin{array}{l}\text { Vildagliptin } \\
50 \mathrm{mg} \text { qd, } n(\%)\end{array}$ & $\begin{array}{l}\text { Placebo, } \\
n(\%)\end{array}$ \\
\hline$n$ & 50 & 55 \\
\hline AEs & $29(58.0)$ & $40(72.7)$ \\
\hline SAEs & $7(14.0)$ & $9(16.4)$ \\
\hline $\begin{array}{l}\text { Discontinuation due to } \\
\text { AEs }\end{array}$ & $2(4.0)$ & $5(9.1)$ \\
\hline Deaths & $0(0.0)$ & $3(5.5)$ \\
\hline \multicolumn{3}{|l|}{ AEs in SOCs } \\
\hline Cardiac disorders & $2(4.0)$ & $10(18.2)$ \\
\hline Gastrointestinal disorders & $4(8.0)$ & $11(20.0)$ \\
\hline $\begin{array}{l}\text { Infections and } \\
\text { infestations }\end{array}$ & $14(28.0)$ & $11(20.0)$ \\
\hline $\begin{array}{l}\text { Musculoskeletal and } \\
\text { connective tissue } \\
\text { disorders }\end{array}$ & $8(16.0)$ & $9(16.4)$ \\
\hline Nervous system disorders & $9(18.0)$ & $15(27.3)$ \\
\hline $\begin{array}{l}\text { Skin and subcutaneous } \\
\text { tissue disorders }\end{array}$ & $5(10.0)$ & $8(14.5)$ \\
\hline \multicolumn{3}{|c|}{ Most common AEs by preferred term ${ }^{a}$} \\
\hline Edema & $6(12.0)$ & $9(16.4)$ \\
\hline Nasopharyngitis & $6(12.0)$ & $4(7.3)$ \\
\hline Dizziness & $2(4.0)$ & $8(14.5)$ \\
\hline Fatigue & $3(6.0)$ & $3(5.5)$ \\
\hline Hyperhidrosis & $1(2.0)$ & $5(9.1)$ \\
\hline
\end{tabular}

$A E$ adverse event, $n$ number of patients with an AE, $S A E$ serious adverse event, SOC system organ class

a $\geq 10 \%$ in the study 
There was no deterioration of renal function with vildagliptin after 24 weeks of treatment as assessed by the eGFR (change from baseline -0.1 vs. $-2.0 \mathrm{ml} / \mathrm{min} / 1.73 \mathrm{~m}^{2}$ with placebo).

\section{DISCUSSION}

The present sub-analysis evaluated vildagliptin in the uniquely vulnerable elderly population $\geq 75$ years with T2DM and moderate or severe RI, many of whom (nearly 70\%) were treated with insulin. The main finding was that vildagliptin was efficacious, with no increase in the rate of hypoglycemia compared to placebo despite a marked improvement in glycemic control.

The magnitude of the glucose-lowering seen in this subgroup $\left(\mathrm{HbA}_{1 \mathrm{c}}\right.$ reduction of $-1.0 \%$ from a baseline of $7.8 \%$ ) was similar to that seen previously in patients $\geq 75$ years with mostly normal renal function or mild RI receiving vildagliptin monotherapy or add-on therapy to metformin ( $-0.9 \%$ to $-1.1 \%)$ [16] or in a population with severe RI with a mean age of 64 years receiving background insulin therapy (-0.9\%) [18], which was also reported to be consistent with that seen for vildagliptin in the general population in monotherapy or combination therapy studies. Relative to placebo, the decrease in $\mathrm{HbA}_{1 \mathrm{c}}(-0.8 \%)$ was clinically meaningful, with more than half of the vildagliptin-treated patients reaching an $\mathrm{HbA}_{1 \mathrm{c}} \leq 7.5 \%$, regarded an appropriate target for this patient population [3, 21, 22]. Thus, the metabolic derangements clearly manifested in this patient population with advanced age, RI, and long-standing mainly insulin-treated T2DM [23] did not adversely affect the efficacy of vildagliptin. The small $\mathrm{HbA}_{1 \mathrm{c}}$ reduction $(-0.2 \%)$ seen in the control group is likely a study effect and not unusual for patients entering a placebo-controlled trial.
Hypoglycemia is a major limiting barrier to good glycemic control even in the general population [15]. In light of the markedly increased risk of hypoglycemia, including severe hypoglycemia, in a highly vulnerable patient population of advanced age, with RI and significant insulin use [2, 8-12] and given the more severe consequences of hypoglycemia in these patients (including events like falls and fractures [2]), as well as the potential CV risk associated with severe hypoglycemia [2, 24], the finding that there was no increase in the rate of hypoglycemia with vildagliptin despite the meaningful decrease in mean $\mathrm{HbA}_{1 \mathrm{c}}(7.8 \%$ to $6.8 \%)$ is noteworthy. The rate of confirmed hypoglycemia was 0.49 vs. 0.96 events per patient-year with vildagliptin and placebo, respectively, with a very low incidence of severe hypoglycemia (1 patient on multiple insulin injections in the vildagliptin group, precipitated by alcohol consumption, and 0 patients in the placebo group) and no discontinuations due to hypoglycemia. While an improvement in glycemic control in the range reported in the current analysis would generally be expected to be associated with an increase in hypoglycemia, in particular, in the patient population studied, the protection against hypoglycemia seen with vildagliptin has a mechanistic basis, likely being mediated via a GIP-induced increase in glucagon levels whenever glucose levels fall into the hypoglycemic range $[14,20]$. Vildagliptin treatment extends the physiological mealrelated increases of the incretin hormones into the inter-meal and overnight periods and vildagliptin was shown to enhance the glucagon counter-regulatory response to hypoglycemia during a stepped clamp versus placebo in drugnaïve patients with T2DM $[14,25]$.

Consistent with the weight neutrality generally reported for vildagliptin [26] including in insulin-treated patients [20], there 
was only a minimal weight change $(0.4 \mathrm{~kg})$ reported for vildagliptin when added to background therapy in the elderly patient group with moderate/severe RI.

The safety and tolerability of vildagliptin in a wide range of disease stages including pooled analyses from a large clinical database was assessed in detail previously $[16,17,20,27-$ 29]. The results from the present investigation are consistent with the safety and tolerability profile reported earlier, with no new safety signals identified in the present sub-analysis. While a numerically lower percentage of vildagliptin-treated patients experienced events in the SOC of Cardiac disorders (4\% vs. $18.2 \%$ ), a trend similar to that seen in an earlier pooled analysis of elderly patients $\geq 75$ years [16], this was not driven by any particular type of events and based on a very small number of events, thus limiting definitive conclusions.

In light of the broader applicability of the reported results, while inclusion/exclusion criteria in clinical trials can restrict the demographic and disease characteristics compared to a real life setting, the patients studied in the present analysis were overall reflective of an elderly patient population with advanced renal insufficiency, thus further extending the findings of a previously pooled analysis of a patient population $\geq 75$ years with mainly normal renal function or mild RI [16] and of a study in a population $\geq 70$ years including a small percentage of patients with moderate RI (14.4\%) but no patients with severe RI [30]. The latter study showed that nearly twice as many patients reached individualized treatment targets with vildagliptin than placebo added to their background therapy, with comparable safety and tolerability. In the present sub-analysis, nearly $1 / 3$ of patients $\geq 75$ years had severe RI and the remaining about $2 / 3$ of patients had moderate RI, with a mean eGFR of $35 \mathrm{ml} / \mathrm{min} / 1.73 \mathrm{~m}^{2}$. In addition to the renal comorbidity, patients also had a high prevalence of $\mathrm{CV}$ risk factors [including obesity (mean BMI $30.5 \mathrm{~kg} / \mathrm{m}^{2}$ ), long-standing T2DM (mean duration of 16.2 years, with $2 / 3$ of patients being diagnosed for $\geq 10$ years), hypertension (>90\%), dyslipidemia (>2/3)], and $>50 \%$ had a high CV risk status based on previous CCV history. These factors, together with the fact that $\sim 70 \%$ of patients were treated with insulin and $\sim 85 \%$ of patients taking $\geq 5$ other medications (in addition to their anti-diabetic treatment), highlight the uniquely fragile/vulnerable characteristics of the studied population. It is worth noting, however, that while the mean age of the population was 78.1 years, the upper age of the patients was 85 years, thus the data cannot necessarily be extrapolated to a population of $>85$ years. Another limitation of the present investigation is that the results are based on a sizeable yet limited number of patients. Furthermore, information that would have allowed to characterize the population with respect to dependency (e.g. care home residency) or mental status is lacking.

\section{CONCLUSION}

Taken together, the present sub-study provides valuable information regarding the experience with vildagliptin in the difficult-to-treat elderly population $\geq 75$ years with $\mathrm{T} 2 \mathrm{DM}$ and moderate or severe RI.

\section{ACKNOWLEDGMENTS}

The authors acknowledge the patients, investigators and staff at participating sites for the study and also thank Monika Kundu for technical help and assistance with the artwork. 
This work and the article processing charges were funded by Novartis Pharmaceuticals Corporation.

Dr. Schweizer is the guarantor for this article, and takes responsibility for the integrity of the work as a whole.

Conflict of interest. Dr. Schweizer is an employee of Novartis and owns shares. Dr. Dejager is an employee of Novartis and owns shares.

Compliance with ethics guidelines. The study underlying this sub-analysis was conducted in accordance with the Helsinki Declaration of 1975, as revised in 2000 and 2008 and Declaration of Helsinki and International Conference on Harmonization/ Good Clinical Practice guidelines. The study protocol was approved by an independent ethics committee/institutional review board (IRB) at each site and all patients provided written informed consent.

Open Access. This article is distributed under the terms of the Creative Commons Attribution Noncommercial License which permits any noncommercial use, distribution, and reproduction in any medium, provided the original author(s) and the source are credited.

\section{REFERENCES}

1. International Diabetes Federation. IDF Diabetes Atlas, 5th edition Brussels, Belgium: International Diabetes Federation, 2011. http://www.idf.org/dia betesatlas/5e/diabetes. Accessed 4 Apr 2013.

2. Bourdel-Marchasson I, Schweizer A, Dejager S. Incretin therapies in the management of elderly patients with type 2 diabetes mellitus. Hosp Pract. 2011;39:7-21.

3. National Kidney Foundation. KDOQI Clinical Practice Guideline for Diabetes and CKD: 2012 update. Am J Kidney Dis. 2012;60:850-86.
4. Joyce AT, Iacoviello JM, Nag S, et al. End-stage renal disease-associated managed care costs among patients with and without diabetes. Diabetes Care. 2004;27:2829-35.

5. Blickle JF, Doucet J, Krummel T, Hannedouche T. Diabetic nephropathy in the elderly. Diabetes Metab. 2007;33:S40-55.

6. Remuzzi G, Schieppati A, Ruggenenti P. Clinical practice. Nephropathy in patients with type 2 diabetes. N Engl J Med. 2002;346:1145-51.

7. Pornet C, Bourdel-Marchasson I, Lecomte P, et al. Trends in the quality of care for elderly people with type 2 diabetes: the need for improvements in safety and quality (the 2001 and 2007 ENTRED Surveys). Diabetes Metab. 2011;37:152-61.

8. Halimi S, Raccah D, Schweizer A, Dejager S. Role of vildagliptin in managing type 2 diabetes mellitus in the elderly. Curr Med Res Opin. 2010;26:1647-56.

9. Chellia A, Burge MR. Hypoglycemia in elderly patients with diabetes mellitus: causes and strategies for prevention. Drugs Aging. 2004;21:511-30.

10. Bremer JP, Jauch-Chara K, Hallschmid M, Schmid S, Schultes B. Hypoglycemia unawareness in older compared with middle-aged patients with type 2 diabetes. Diabetes Care. 2009;32:1513-7.

11. Gerich JE, Meyer C, Woerle HJ, Stumvoll M. Renal gluconeogenesis: its importance in human glucose homeostasis. Diabetes Care. 2001;24:382-91.

12. Moen MF, Zhan M, Hsu VD, et al. Frequency of hypoglycemia and its significance in chronic kidney disease. Clin J Am Soc Nephrol. 2009;4:1121-7.

13. Arem R. Hypoglycemia associated with renal failure. Endocrinol Metab Clin N Am. 1989;18:103-21.

14. Ahren B, Schweizer A, Dejager S, Villhauer EB, Dunning BE, Foley JE. Mechanisms of action of the DPP-4 inhibitor vildagliptin in man. Diabetes Obes Metab. 2011;13:775-83.

15. Dejager S, Schweizer A. Minimizing the risk of hypoglycemia with vildagliptin: clinical experience, mechanistic basis, and importance in type 2 diabetes management. Diabetes Ther. 2011;2:51-66.

16. Schweizer A, Dejager S, Foley JE, Shao Q, Kothny W. Clinical experience with vildagliptin in the management of type 2 diabetes in a patient population $\geq 75$ years: a pooled analysis from a database of clinical trials. Diabetes Obes Metab. 2011;13:55-64. 
17. Lukashevich V, Schweizer A, Shao Q, Groop PH, Kothny W. Safety and efficacy of vildagliptin versus placebo in patients with type 2 diabetes and moderate or severe renal impairment: a prospective 24-week randomized placebo-controlled trial. Diabetes Obes Metab. 2011;13:947-54.

18. Lukashevich V, Schweizer A, Foley JE, Dickinson S, Groop PH, Kothny W. Efficacy of vildagliptin in combination with insulin in patients with type 2 diabetes and severe renal impairment. Vasc Health Risk Manag. 2013;9:21-8.

19. Dejager S, Schweizer A. Incretin therapies in the management of patients with type 2 diabetes mellitus and renal impairment. Hosp Pract. 2012;40:7-21.

20. Schweizer A, Foley JE, Kothny W, Ahrén B. Clinical evidence and mechanistic basis for vildagliptin's effect in combination with insulin. Vasc Health Risk Manag. 2013;9:57-64.

21. Inzucchi SE, Bergenstal RM, Buse JB, et al. Management of hyperglycaemia in type 2 diabetes: a patient-centered approach. Position statement of the American Diabetes Association (ADA) and the European Association for the Study of Diabetes (EASD). Diabetologia. 2012;55:1577-96.

22. Sinclair AJ, Paolisso G, Castro M, BourdelMarchasson I, Gadsby R, Rodriguez Mañas L; European Diabetes Working Party for Older People 2011. Clinical guidelines for type 2 diabetes mellitus (EDWPOP). Diabetes Metab. 2011; 37: S27-38.

23. Ferrannini E, Groop PH, Nauck M, Fioretto P, Hach $\mathrm{T}$, Thomas $\mathrm{M}$. The significance of the kidney in diabetes. Konigswinter: infill Kommunikation $\mathrm{GmbH} ; 2012$.

24. Bonds DE, Miller ME, Bergenstal RM, et al. The association between symptomatic, severe hypoglycemia and mortality in type 2 diabetes: retrospective epidemiological analysis of the ACCORD study. BMJ. 2010;340:b4909.

25. Ahren B, Schweizer A, Dejager S, et al. Vildagliptin enhances islet responsiveness to both hyper- and hypoglycemia in patients with type 2 diabetes. J Clin Endocrinol Metab. 2009;94:1236-43.

26. Foley JE, Jordan J. Weight neutrality with the DPP-4 inhibitor vildagliptin: mechanistic basis and clinical experience. Vasc Health Risk Manag. 2010;6:541-8.

27. Ligueros-Saylan M, Foley JE, Schweizer A, Couturier A, Kothny W. An assessment of adverse effects of vildagliptin versus comparators on the liver, the pancreas, the immune system, the skin and in patients with impaired renal function from a large pooled database of Phase II and III clinical trials. Diabetes Obes Metab. 2010;12:495-509.

28. Schweizer A, Dejager S, Foley JE, Kothny W. Assessing the general safety and tolerability of vildagliptin: value of pooled analyses from a large safety database versus evaluation of individual studies. Vasc Health Risk Manag. 2011;7:49-57.

29. Schweizer A, Dejager S, Foley JE, Couturier A, Ligueros-Saylan M, Kothny W. Assessing the cardio-cerebrovascular safety of vildagliptin: metaanalysis of adjudicated events from a large Phase III type 2 diabetes population. Diabetes Obes Metab. 2010;12:485-94.

30. Strain WD, Lukashevich V, Kothny W, Hoellinger MJ, Paldánius PM. Individualised treatment targets for elderly patients with type 2 diabetes using vildagliptin add-on or lone therapy (INTERVAL): a 24 week, randomised, double-blind, placebocontrolled study. Lancet. 2013 (Epub ahead of print). 